\title{
Servicescape failure and recovery strategy in the Food Service Industry: The effect on customer repatronization.
}

\begin{abstract}
This study addresses the servicescape failures in food service industry related to the poor management of physical environments and the associated recovery strategies used to retain dissatisfied customers. Despite the acknowledged importance of servicescapes, there is a dearth of exploratory investigation on servicescape failures and recovery strategies, and on the ways these influence the subsequent behavior of customers. Using the critical incident technique (CIT), data on 226 servicescape failures and 29 recovery strategies were collected from 174 informants by personal interview. The content analysis revealed that cleanliness issues were the most reported problem in food service industry, followed by other issues regarding the design, social interaction, and functionality. The implemented recoveries were perceived both positively and negatively by the informants. The findings signify that in the case of servicescape failures, it is generally more difficult to execute an effective recovery and gain customers' repatronization. It is highly recommended that food service practitioners should closely monitor the servicescapes and implement appropriate recovery strategies which may greatly affect customer satisfaction and repatronage behavior.
\end{abstract}

Keyword: Servicescape failure; Recovery strategy; Repatronage behavior; Food service industry; Critical incident technique. 